\title{
O que há de errado com a democracia liberal?
}

Uma das dificuldades na aceitação da democracia liberal reside em que os que discordam de um consenso em geral formulam as frases mais sagazes, enquanto os que defendem o statu quo caem no argumento de senso comum e têm pouco apelo intelectual. ${ }^{1} \mathrm{O}$ secular confronto entre o liberalismo e seus críticos parece um exemplo dessa regra. Comparada às alternativas, a tradição liberal teve sua vida facilitada nas democracias ocidentais e, embora seus expoentes mais rigorosos possam indicar um acúmulo de casos em que a prática fica aquém da teoria, o liberalismo em geral ocupa o lugar central. Talvez por isso, seus defensores recorram a argumentos tão pouco inspiradores. Há ocasionais voos de imaginação que emprestam à tradição liberal o aspecto de grande teoria: recentemente, Fukuyama (1989) coloca os sucessos políticos do liberalismo num quadro ambiciosamente hegeliano, e proclama o fim da história como resultado. Com maior frequência, porém, o liberalismo deriva sua força do fato de que é comum e, portanto, faz mais sentido.

Aqueles que acham o liberalismo insuficiente desenvolveram críticas muito poderosas e, para qualquer um que se incline ao argumento teórico, oferecem satisfação mais considerável. Em geral prefaciando suas alternativas com uma análise cuidadosa dos supostos e falhas do liberalismo, suas observações são imaginativas e astuciosas. Os defensores nem sempre respondem

Do original "So what's wrong with liberal democracy?", publicado como o capítulo 6 do livro Engendering democracy. Direitos autorais concedidos pela Polity Press Ltd. Traduzido por Plinio Dentzien. Revisão da tradução por Flávia Biroli.

- Revista Brasileira de Ciência Política, no 6. Braślia, julho - dezembro de 2011, pp. 339-363. 
no mesmo nível. Karl Popper (1945), por exemplo, caiu muito abaixo de seu padrão usual de rigor ao criticar Hegel e Marx, baseando-se tanto no que ouviu dizer quanto em análise de textos. Outros se contentaram a salpicar suas respostas com referências fáceis à sociedade totalitária ou com acenos de desprezo a sonhos utópicos, e não se preocuparam com uma refutação sistemática. A disputa foi assim desigual, com as complacências do senso comum, de um lado, e teorias intricadas, de outro; se a democracia liberal triunfou no domínio da prática política, não pode afirmar que tenha triunfado na batalha das idéias. Embora questionado de uma variedade de ângulos - inclusive o feminista, o republicano e o da participação -, o liberalismo raramente se importa em ser sagaz.

Isso cria um desequilíbrio nos debates, e o próprio engenho das alternativas pode fazê-las parecer mais substanciais do que de fato são. Sobre a questão judaica, de Karl Marx, por exemplo, escrito em 1843, tem sido referência para muitas análises da tradição liberal e, com seus surpreendentes contrastes entre a universalidade celestial da cidadania liberal e as sujas explorações da esfera privada, construiu a agenda para muitas críticas posteriores (Marx e Engels, 1975). Mas a alternativa que Marx desenvolveu não foi satisfatória e, ainda que sua concepção da liberdade seja ainda considerada por muitos como "muito mais profunda e rica que posições liberais clássicas ou negativas” (Lukes, 1985, p. 149), sua noção de democracia continua utópica ou vaga. Levadas pela força da análise, as pessoas nem sempre se detiveram a considerar todas as consequências; essa falha deixou o marxismo profundamente defensivo em face das recentes revoluções democráticas.

A questão não é exigir que os críticos desenvolvam uma alternativa completa antes que seja possível julgar a validade de sua crítica: se fossemos erigir esse padrão, haveria pouco campo para o desenvolvimento de ideias. $\mathrm{O}$ feminismo tem sido visto como um acréscimo de peso decisivo às críticas à democracia liberal e tem considerado essa tradição como particularmente resistente às preocupações de gênero. No entanto, como Carole Pateman corretamente observa na conclusão de The sexual contract:

A recuperação da história do contrato sexual não fornece em si mesma um programa político nem oferece qualquer atalho para a árdua tarefa de decidir quais, em circunstâncias dadas, os melhores cursos de ação e políticas para as feministas, ou ainda quando e como as feministas devem fazer alianças com outros movimentos 
políticos. Contada a história, porém, surge uma nova perspectiva a partir da qual avaliar as possibilidades políticas... Quando a história reprimida da gênese política é trazida à superfície, a paisagem política nunca mais poderá parecer a mesma. (PATEMAN,1988, p. 233)

O gênero muda e deve mudar o modo como pensamos a democracia, mas, dada a força das tradições existentes, transcorrerá algum tempo até que os detalhes da nova paisagem se tornem claros. Também não devemos supor rapidamente demais que todas as suas características mudarão.

\section{De indivíduos a grupos}

Entre as questões que surgiram na teoria feminista, as mais provocantes são centradas na universalidade. Grande número de contribuições recentes investiga a noção de que a democracia significa tratamento igual e questiona a ideia de que os cidadãos devem deixar seus corpos - portanto a si mesmos - para trás quando entram na arena pública. Como argumentam Carole Pateman (1988), Zillah Eisenstein (1989), Iris Marion Young (1989) e outras, não há indivíduo neutro quanto ao gênero e, quando os liberais tentam lidar conosco apenas em nossa condição de cidadãs abstratas, estão desejando apagar não apenas diferenças de classe, mas aquelas que podem ser diferenças ainda mais intransigentes de sexo. A democracia liberal deseja ignorar (e o republicanismo cívico deseja transcender) todas as identidades e diferenças mais locais; na realidade, as duas tradições insinuam o corpo masculino e a identidade masculina em suas definições da norma. Os democratas liberais, em particular, acreditam ter estendido todos os direitos e liberdades necessários às mulheres ao permitir-lhes o voto nos mesmos termos dos homens. Isso é simplesmente inadequado, como até os indicadores mais crus (como o número de mulheres na política) mostram. A democracia não pode pairar acima da diferença sexual, mas tem que ser redefinida com essa diferença em mente. Uma implicação óbvia é que a democracia deve lidar conosco não apenas como indivíduos, mas como grupos.

Penso que isso está certo, e qualquer argumento em favor do aumento da representação das mulheres na política se funda em alguma posição desse tipo. A composição de nossas assembleias eleitas está em causa porque as pessoas não são todas as mesmas, e o fato de que elas sejam tão consistentemente enviesadas em direção a certas categorias ou grupos é evidência 
suficiente para isso. Quando as características dos eleitos se desviam em grau significativo daquelas do eleitorado como um todo, há um caso claro para dizer que algo está errado. Essas "características" são obviamente relevantes por si mesmas, e alguns grupos se tornam mais poderosos do que os outros.

Muitos liberais estão preparados para chegar até este ponto, é claro. Os liberais têm créditos em questões de discriminação - às vezes mais que seus críticos mais radicais - e a maioria deles expressará satisfação quando mais mulheres e pessoas de minorias étnicas forem eleitas. Os melhores entre os liberais, entretanto, ainda acham difícil mudar seu foco dos indivíduos para grupos. A oposição à discriminação que informa grande parte do liberalismo contemporâneo implica em remover obstáculos que bloqueiam o caminho de um indivíduo e aplaudir quando esse indivíduo tem sucesso. O problema é ainda percebido em termos dos maus tratos prévios, que julgaram e puseram de lado pessoas porque se desviaram de alguma norma preconceituosa. A resposta é apresentada em termos de tratá-las, em vez disso, apenas como pessoas.

A permanente tensão entre aqueles que defendem oportunidades iguais e os que sublinham a importância da ação afirmativa é um exemplo do abismo que separa a antidiscriminação liberal e os mecanismos que assegurariam efetivamente uma representação igual das mulheres. Tão logo o argumento se move para o domínio dos mecanismos e garantias, passa a ameaçar os princípios fundadores da democracia liberal. Num nível prático isso diz respeito à livre escolha de eleitorados partidários. A ideia de assentos garantidos para mulheres, ou quotas de $40 \%$ para cada sexo, inevitavelmente cerceia a liberdade daqueles que selecionam os candidatos e, nessa medida, entra em conflito com ideais liberais. De modo mais fundamental, porém, qualquer medida destinada a assegurar uma representação aumentada das mulheres está afirmando que a diferença sexual é politicamente relevante e que a democracia deve reconhecer grupos. Indo um passo além da noção de justiça para as mulheres (melhorando seu acesso, se quiserem, a carreiras políticas), diz que nossas assembleias não são representativas quando são enviesadas em direção a um dos sexos. Quando nos movemos para o terreno dos mecanismos, como com certeza devemos, lidamos explicitamente com a diferença e com o reconhecimento dela como questão política.

Deixando de lado a opção que nos aconselha a continuar de qualquer modo, há apenas duas aproximações sérias à sub-representação das mulheres. 
A primeira amplia o pensamento liberal democrático, mas pode ser tornada compatível com ele. Ela identifica obstáculos adicionais ao envolvimento político que muitas pessoas têm ignorado até aqui, inclusive, por exemplo, as horas de trabalho e condições de conselhos e assembleias, os preconceitos e convenções através dos quais os partidos selecionam seus candidatos e, no caso dos EUA, a absurda quantidade de dinheiro que se espera que os candidatos gastem. Onde qualquer dessas condições pode ser apontada como algo que discrimina especificamente contra as mulheres candidatas, as barreiras deverão ser reduzidas ou removidas. Este argumento pode empurrar a democracia liberal até seus limites, pois introduz questões que costumavam ser pensadas como assuntos pessoais ou privados. Mas, como diz respeito a remover barreiras, e sem ainda ditar o resultado eventual, está de acordo com os ideais liberais. Significa que as mulheres não continuarão a ser ativamente excluídas, mas deixa a elas, enquanto indivíduos, a conquista de suas novas oportunidades de envolvimento.

A segunda alternativa se recusa a assumir esse risco e, como nas estratégias recentemente adotadas por vários partidos políticos, inscreve procedimentos que assegurem um resultado mais equilibrado. As pessoas frequentemente debatem essas alternativas como se elas refletissem apenas graus diferentes de determinação à mudança: a primeira, uma pia resolução que remove as barreiras, mas que quase certamente deixará as coisas como estão; a segunda, um compromisso mais dedicado que entende a força da resistência à representação das mulheres e sabe que só garantias alterarão os resultados. Esse é um elemento do argumento, mas os fundamentos políticos são também muito diferentes. A primeira abordagem continua a olhar-nos em nosso caráter de indivíduos abstratos e se concentra em reduzir a relevância de nosso sexo. A segunda reconhece que a sociedade é composta de grupos diferentes e que esses grupos podem desenvolver interesses diferentes. Por causa disso, esta última não deixa ao acaso a proporcionalidade. A primeira abordagem diz que não deve fazer diferença se somos mulheres ou homens, e que devemos assegurar-nos de que os procedimentos são genuinamente neutros; a segunda diz que os sexos têm diferentes níveis de poder e que a distribuição deve ser tornada igual.

A despeito de minhas reservas sobre o que pode significar "representação das mulheres", a segunda alternativa é a defendida neste texto. $\mathrm{O}$ cânone liberal insiste em que as diferença entre nós não devem importar, mas em so- 
ciedades dirigidas por grupos de interesses, é desonesto pretender que somos o mesmo. Minha própria visão de um futuro desejável é de fato andrógina a ponto de estar fora de moda, e anseio por uma época quando pudermos ser tratadas como pessoas e não mais como mulheres e homens. Mas uma coisa é desejar esse futuro e outra, muito diferente, apagar as diferenças. As estruturas políticas e econômicas das sociedades contemporâneas exibem alto grau de discriminação sexual e racial e, onde há grupos definíveis, há inevitavelmente interesses de grupo. Portanto, um dos princípios que deve informar as práticas de uma democracia é que os representantes devem espelhar a composição sexual, racial e, onde for relevante, nacional, da sociedade como um todo, e de que devem existir mecanismos para alcançar esse efeito. Tal proporcionalidade seria automática se não houvesse interesses estabelecidos nem estruturas sustentando o poder de grupos; se o número de eleitos fosse suficientemente grande, o princípio da seleção aleatória seria suficiente para alcançar resultados proporcionais. Que isso ainda não tenha acontecido demonstra a necessidade de mudança. Quando um grupo é consistentemente sub-representado, algum outro grupo está obtendo mais do que o que lhe corresponde.

O princípio do espelho pode, é claro, ser estendido a outras divisões, e faz parte da natureza da política que as pessoas defendam os grupos relevantes. Os mais óbvios para começar são aqueles que têm fundamento biológico, pois não há argumento que possa legitimamente ligar o sexo ou a raça das pessoas à sua adequação ao palco da política. Se as mulheres não são eleitas na mesma proporção que os homens, e os africanos ou asiáticos em proporção aproximada a seus números no eleitorado como um todo, algo suspeito está acontecendo (suspeito, mas não particularmente obscuro). A questão mais difícil é até onde estender a ênfase nos grupos. A alternativa mais forte à abstração do indivíduo é considerar as pessoas apenas em suas identidades altamente especificadas e diferenciadas: como mulheres ou homens, como negros ou brancos, como empregados ou patrões. (A lógica poderia nos levar a autodefinições ainda mais detalhadas, como os HJD, homens judeus divorciados, ou a MBS, mulher branca solteira, da coluna de corações solitários da New York Review of Books). Isso envolveria bem mais que os mecanismos para aumentar o número de mulheres eleitas e também consideravelmente mais que a proposta de Iris Young de um poder de veto para grupos oprimidos. Se as pessoas fossem consideradas apenas a partir 
de suas identidades de grupo, então a democracia se tornaria uma questão de representação de grupos, e a questão-chave seria como identificar e representar cada um desses grupos.

Não seguirei essa via, mas ainda há algumas diferenças que devem ser consideradas. Tomemos, por exemplo, a gama de características - nação de origem, religião, orientação sexual - que se tornam mais ou menos importantes à medida que mudam as circunstâncias. $\mathrm{O}$ argumento da probabilidade estatística se aplica aqui como em qualquer outro lugar, embora a evidência seja menos conclusiva se o grupo for pequeno. ( $\mathrm{O}$ acaso por si só poderia explicar por que ninguém do grupo foi eleito). Mas a importância que as pessoas atribuem a alcançar a proporcionalidade em termos dessas características depende de elas se definirem primariamente nesses termos e de elas considerarem esses aspectos como incidentais ou essenciais. Como regra, é claro, os grupos veem a si mesmos nesses termos quando experimentaram opressão por causa dessa característica definidora. Atingido esse ponto, alguma forma de sistema de quotas parece uma demanda legítima.

A prática do que é conhecido como democracia consociacional é a que chega mais próxima de reconhecer isso e construir uma proteção para os que são considerados grupos sociais chave. A justificativa oficial é que em certos países as pessoas podem de fato ser definidas por uma característica, quando a sociedade é tão segmentada que, em cada questão importante, as pessoas se alinham consistentemente com apenas um grupo. Daí, na Holanda, os recursos do governo são tipicamente distribuídos entre os três principais grupos religiosos (católicos, calvinistas e seculares) em proporção à sua parte na população como um todo. Esse sistema reconhece a força da identidade e adesão ao grupo, ainda que os partidos políticos continuem a disputar as eleições numa base mais ampla, e os grupos não se tornem um substituto para a política propriamente dita. Mesmo quando heterogeneidade e a diferença entre grupos são explicitamente reconhecidas, as pessoas relutam em reduzir tudo a isso.

Naquelas partes da África onde há um histórico de tensão étnica e uma correlação continuada entre etnicidade e poder político e econômico, os governos algumas vezes desenvolveram mecanismos para assegurar a cada grupo algum grau de representação. A Nigéria, por exemplo, experimentou extensamente sistemas de quotas e estruturas federais que devolvem poder aos estados locais, e foi o prematuro desafio ao federalismo que em parte 
provocou a guerra civil dos anos 60 . Esse é um contexto em que algumas garantias de poder proporcional são certamente necessárias, pois, onde houve o privilégio de certos grupos sobre outros, precisam existir procedimentos para contrabalançar esses efeitos. Precisamente quais mecanismos são mais apropriados é sempre mais difícil de estabelecer, pois qualquer opção escolhida pode gerar tanta tensão quanto a que pretende dissolver. Assim, de um lado, haverá pressão para reconhecer mais e mais grupos como merecedores de alguma forma de proteção via quotas (a Nigéria, por exemplo, sofreu uma proliferação de estados); de outro, haverá tensão entre a proporcionalidade e os princípios do mérito. O mais problemático de tudo é o conservadorismo potencial, pois se a esperança é que a religião e a etnicidade percam sua significação política e econômica e não mais determinem o acesso das pessoas à renda ou ao poder, então inscrever garantias poderá ser em algum ponto contraproducente. Continuando com o exemplo da Nigéria, onde os partidos políticos tenderam a reproduzir uma divisão étnica tripartite, a preparação para o retorno ao governo civil em 1992 agora trata isso como o problema: a atual proposta é que só dois partidos poderão se registrar e competir.

Essas questões são complicadas demais para respostas fáceis, mas os argumentos sobre a sub-representação das mulheres precisam considerá-las como possíveis ramificações. Observei em outro lugar que ninguém deve ser impedido de argumentar a favor da igualdade sexual pela reductio ad absurdum que propondo estender esse mesmo princípio a uma infinidade de grupos concebíveis. Alguma extensão é, porém, apropriada, e um princípio útil é que, quando uma característica particular passa a fazer diferença (significando que ela dita substancialmente o destino das pessoas que define), deve haver algum mecanismo que assegure representação proporcional a esse grupo. Quando a característica perder sua significação determinante, esses mecanismos deverão cessar. As técnicas possíveis incluem a ação afirmativa ou sistema de quotas a ser adotado pelos partidos políticos; nos casos mais agudos, eles podem também operar no nível do governo, garantindo postos em alguma proporção aos números no eleitorado como um todo. A dificuldade óbvia é saber quando algo "faz diferença," e quanta diferença deve fazer antes que o mecanismo seja acionado. A obra de Iris Young (1988) na identificação de grupos oprimidos avança na direção dessas questões, mas os problemas apenas começam a entrar no debate. 
A última candidata para a proporcionalidade é a classe, e o princípio do espelho disfarça o problema. As pessoas convencionalmente justificam o ínfimo número de trabalhadores eleitos como representantes dizendo que eles não são excluídos por causa da classe, mas porque lhes faltam as qualificações apropriadas. O envolvimento na política está associado a certas habilidades ou qualificações, e ainda que não haja base para fundar essas qualificações na origem de classe de uma pessoa (elas não dependem de quem sejam seus pais), podem estar associadas a certos tipos de ocupação ou experiência (advogados são bons em discursos, enquanto um assistente administrativo pode não ter grande experiência do mundo). Em outras palavras, a classe pode ser uma consideração relevante, de modo que, se a composição de uma assembleia eleita se desvia na direção de um extremo do espectro de classes, há uma causa inocente e defensável. Uma causa, porém, pode ser completamente inocente, tendo um efeito injusto. Quando a classe estrutura os interesses, prioridades e percepção do mundo das pessoas em tal grau, seria um problema para a democracia se aqueles que tomam as decisões viessem majoritariamente de uma classe minoritária. Aneurin Bevan acreditava que só se poderia falar de representação plena quando a pessoa eleita "falasse com os sotaques autênticos de seus eleitores", compartilhasse seus valores e estivesse "em contato com suas realidades" (apud Arblaster, 1987, p. 84). Há suficiente verdade nisso (e mais que suficiente paralelo com o que as feministas defendem em relação às mulheres) para justificar uma discussão e reflexão mais completas.

Em relação a todos os candidatos à representação de grupos, há, contudo, uma grande dificuldade: que há tantos grupos aos quais cada um de nós pode, em princípio, pertencer. A poeta June Jordan comenta que "cada uma de nós é mais do que qualquer raça que representemos e mais que qualquer categoria de gênero em que estivermos inseridas. Nós temos outros tipos de adesão, outros tipos de sonhos" (apud Parmaar, 1989). Não caímos simplesmente em uma ou outra definição; tipicamente na política, cada uma de nós oscila entre muitas identidades, formando e reformando alianças, tentativas que podem não sobreviver ao problema corrente. E, da mesma forma, para uma linha comum que liga sexismo, racismo, nacionalismo e religião, o fanatismo é a definição do eu e dos outros por uma única característica, sendo incapaz de ver qualquer coisa mais. Em sua maioria, no entanto, as pessoas existem dentro de identidades múltiplas, cada uma 
das quais pode se tornar temporariamente dominante. Em alguns contextos, as pessoas se identificam primariamente com aquelas da mesma raça; em outros, com as do mesmo sexo. Às vezes é a classe que forja as conexões; às vezes a nacionalidade; muito frequentemente, os ideais e crenças. Como afirmei em outro lugar:

Vivemos numa sociedade de classes que é também estruturada pelo gênero, o que quer dizer que homens e mulheres experimentam a classe de maneiras diferentes, e que as unidades potenciais de classe são desorganizadas por conflitos de gênero. Invertendo a ênfase: vivemos numa ordem de gênero que também é estruturada pela classe, o que quer dizer que as mulheres experimentam sua feminilidade de maneiras diferentes, e que sua unidade enquanto mulheres é continuamente desorganizada por conflitos de classe. Trazendo a raça para completar o triângulo, pode se ver quão complexa se torna a geometria. Ninguém é "simplesmente" um trabalhador, uma mulher, um negro. A noção de que nossa política pode simplesmente refletir uma de nossas identidades parece implausível ao extremo. (PHILLIPS, 1987, p. 12)

Uma implicação disso é que, enquanto qualquer sistema que se diga democrático deve ser capaz de assegurar que seus representantes espelhem a composição étnica e sexual da população, esses representantes não devem ser vistos como "representando" seu grupo étnico ou seu sexo. Argumentei antes que poderia ser profundamente não democrático se as mulheres representantes fossem consideradas como falando apenas ou até principalmente pelas mulheres, particularmente quando não há mecanismos substanciais para estabelecer o que as "constituintes" apoiam. Acrescento agora que é muito limitante olhar tanto as eleitas como o eleitorado a partir de uma só definição de identidade e, particularmente, quando se tratar de uma identidade que não especifica crenças particulares. As feministas estão certas quando argumentam que as pessoas não devem deixar de lado suas identidades sexuais quando alcançam a arena política. Mas elas tampouco devem definir-se por somente um critério, nesse caso, apenas o gênero.

\section{O liberalismo como um mundo de muros}

Em questões de representação política, a ênfase em grupos que são diferentes por oposição aos indivíduos que são em princípio o mesmo é uma correção importante à abordagem liberal tradicional, e leva com ela implicações específicas sobre a garantia de representação proporcional para os 
grupos. Aqueles que ignoram o sexo dos candidatos não são tão justos como podem acreditar, pois, na medida em que as sociedades são organizadas pela diferença sexual e cada sexo tem suas próprias tarefas, identidades, responsabilidades e papéis, devem existir mecanismos para assegurar a paridade na distribuição do poder. Como o outro lado do meu argumento é que qualquer discrepância entre a proporção de mulheres no eleitorado e a proporção de mulheres eleitas é prova suficiente de que a sociedade é ordenada sexualmente, não haverá momento em que esse imperativo perca sua força. Ou a sociedade trata os homens e as mulheres como genuinamente iguais, caso em que aparecerão em números iguais em cada fórum de tomada de decisões, ou os trata de maneira injusta, caso em que precisamos de arranjos especiais para garantir uma presença igual.

Isso desafia e transforma alguns dos princípios fundadores do liberalismo, mas fica aquém de uma completa reversão. Notadamente, não defendi a representação de grupos no sentido mais substancial de as pessoas serem representadas apenas e sempre como grupos; e continuo a pensar na política como meio de discutir e representar crenças que são variadas e individuais. Sigo uma via de moderação semelhante em minha conclusão sobre a divisão entre público e privado. Aí também vejo o liberalismo submetido a sérias críticas, mas não abandonado pelo extremo oposto. O liberalismo é peculiarmente infenso ao gênero, e as distinções que estabelece entre as esferas pública e privada são particularmente adequadas para manter a subordinação política das mulheres. Argumentos que desprezam a relevância política da esfera privada estão contribuindo para manter as coisas como estão, pois nos encorajam a considerar que tudo vai bem a despeito do que deveria ser considerado como grandes contradições. A tirania doméstica, por exemplo, é e deve ser considerada como inteiramente em contradição com a cidadania, pois, por trás da fachada dos direitos iguais à participação e ao voto, ela segue como antes da luta por esses direitos e sua conquista. Até nos exemplos mais comuns, nos quais se "permite" que as mulheres decidam por si mesmas se vão a uma reunião ou em quem votar, o fato de que algo lhes seja permitido deve nos alertar para a inconsistência do modo como a cidadania igual está sendo proposta. Nas condições aparentemente mais iguais, as desigualdades continuadas da divisão do trabalho ainda condenam as mulheres a um papel político menor. Frequentemente excluídas pela falta de tempo ou de confiança, elas não têm o mesmo peso que os homens. 
Graduados das universidades de Oxford e de Cambridge tinham direito a dois votos nas eleições gerais, e só em 1948 essa qualificação extraordinária do princípio de "uma pessoa, um voto" deixou de existir. A obsessão liberal com a divisão entre público e privado oculta e legitima uma desigualdade de pesos ainda mais prejudicial. Fazendo de conta que direitos iguais ao voto são tudo o que importa, recusa-se a envolver-se com as limitações impostas às mulheres por sua posição na esfera doméstica.

Nessa questão, a política do gênero repete a crítica feita muitas vezes em relação à classe: que a igualdade formal pode combinar-se facilmente com o privilégio sistemático e não basta por si mesma. A novidade no feminismo é a extensão disso para o lar e a esfera familiar. A divisão doméstica do trabalho tem consequências diretas na natureza e no grau de envolvimento político e por isso deve ser considerada como um problema político e não apenas social. Qualquer um que se ocupe da igualdade sexual argumentará a favor de uma importante redistribuição das tarefas e responsabilidades domésticas, de modo a igualar o trabalho de homens e mulheres; o que ficou claro é que esse é também um imperativo da democracia. As igualdades formais concedidas pelo sufrágio universal não fazem o que dizem ter feito, pois, sem as mudanças materiais mais substanciais, cada mulher conta como menos que uma. Contar como meio é melhor do que não contar, e ninguém despreza a importância do direito feminino ao voto. Mas a questão em relação ao sufrágio universal é que ele trata cada pessoa como tendo peso igual à outra; se é assim, a questão está longe de ser resolvida.

Uma aproximação da democracia do ponto de vista do gênero sublinha, portanto, igualdades domésticas como parte daquilo que equilibra o peso político das pessoas e as inclui em sua avaliação do que a democracia alcançou. Não que essa seja a única medida. Posso conceber, por exemplo, uma sociedade que desgastou substancialmente a divisão sexual do trabalho, mas em que ninguém tem direito ao voto, e seria no mínimo excêntrico apresentar esse caso como mais democrático que o de uma sociedade na qual as eleições fossem a norma. Mas, na medida em que a divisão do trabalho entre homens e mulheres tem consequências políticas, ela tem que fazer parte do debate político. Nas longas discussões entre liberais e socialistas, a significação da igualdade formal versus a substantiva foi contestada como se se referisse apenas a questões relativas à propriedade. Uma das contribuições básicas do feminismo às nossas ideias sobre a democracia foi ter levantado a cortina sobre essa esfera privada. 
Existe uma versão mais assertiva disso, em que as feministas ressaltam não só as consequências "políticas" de arranjos "privados", mas a relevância da democracia para todos os aspectos da nossa vida social. Anthony Arblaster observou que "no pensamento político clássico, democracia era o termo não só de uma forma de governo, mas de toda uma sociedade, e era habitualmente associada, por seus críticos e inimigos, tanto quanto por seus defensores, com o princípio da igualdade social" (ARBLASTER, 1987, p. 81). Sabemos que isso estava longe da verdade e que os mais fervorosos defensores da igualdade social só eram capazes de concebê-la como questão entre homens. Mas com os ajustes necessários ao gênero, essa descrição captura muitas preocupações feministas. Na política feminista contemporânea, a democracia é em geral apresentada como algo que deve entrar no tecido de todas as relações sociais, e certamente não deve ser restrita ao modo como os governos funcionam. Onde há decisões, há uma questão de democracia, e, ainda que alguns contextos se prestem a procedimentos mais formais do que outros, todos devem ser informados pelos mesmos princípios de respeito igual. Todas aquelas que aderiram ao movimento das mulheres a partir de experiência prévia em política radical, ou da parceria com um homem "radical", falaram repetidamente sobre o abismo que encontraram entre a teoria e a prática, e a maneira como os democratas aparentemente mais progressistas distinguiam entre problemas públicos e privados. Onde as intenções eram supostamente tão boas, os contrastes eram ainda mais evidentes. Mas em outras situações também as mulheres se encontram continuamente numa mistura implausível de igualdade pública e subordinação privada. Uma democracia "de gênero" deve questionar e subverter essa divisão.

O feminismo multiplica os lugares dentro dos quais a democracia parece relevante, e então também altera as dimensões. Os “detalhes” fazem diferença. Essa é uma das mensagens mais poderosas do movimento contemporâneo das mulheres, estendendo-se para além da igualdade sexual especificamente em direção de considerações mais gerais sobre como as pessoas se relacionam. A democracia liberal muitas vezes parece ver o direito igual ao voto como o ápice da sociedade democrática. A concepção mais ampla que se desenvolve a partir de uma análise das mulheres a trata mais como um alicerce sobre o qual a democracia pode ser construída. Uma objeção padronizada à democracia liberal é que ela é mínima em seus ideais: que o "momento" do consentimento é muito pouco frequente para ser levado em 
conta; que a participação foi reduzida a um nível quase gestual; e que, embora o gesto faça diferença (ele ainda decide qual será o governo), não pode ser seriamente apresentado como decisão ou controle. A ênfase no detalhe vem de um ângulo diferente, sublinhando não tanto o grau de controle que as pessoas foram capazes de estabelecer sobre as decisões, mas sim se elas se relacionam como politicamente iguais. Os meios, em outras palavras, são tão importantes quanto os fins. Se a suposta igualdade do voto for continuamente minada por padrões de patronagem, subserviência e condescendência, então a sociedade não é democrática.

Nenhum desses argumentos se ajusta bem à tradição liberal, e todos eles questionam a relação entre as esferas pública e privada. Michael Walzer descreve o liberalismo como "um mundo de muros", cada um dos quais cria uma nova liberdade (Walzer, 1984, p. 315), e retrabalha isso em seu argumento de que a justiça é uma questão de manter os limites entre as esferas. O sucesso no comércio, por exemplo, não deve carregar consigo qualquer poder particular na política; a excelência no trabalho intelectual não deve dar direito a mais de um voto. As esferas da justiça de Walzer (1983) captura muitas das objeções das pessoas à tirania, ao nepotismo ou à corrupção, mas o argumento também é inquietante, pois torna mais difícil criticar os princípios que podem operar em cada esfera separada. Assim, quem sabe o sexo deveria ditar a divisão do trabalho nos lares, desde que não ditasse os arranjos que se aplicam nas escolas? Talvez a força física devesse ser uma consideração apropriada, desde que se limitasse a seu próprio domínio legítimo?

Walzer fala da opressão das mulheres em termos das "estruturas do parentesco" (não é claro o que se inclui nisso) que se reiteram ilegitimamente através de outras esferas distributivas. Elas afetam, portanto, o acesso das mulheres a empregos, educação e, num período anterior, também ao voto. Em outras palavras, não há nada particularmente errado com o que acontece dentro da família. Os problemas começam quando o sexo ou "posição no parentesco" se afasta de seu domínio correto. "A real dominação das mulheres tem menos a ver com seu lugar familiar do que com a exclusão de todos os demais lugares" (Walzer, 1983, p. 240). Isso é semelhante ao argumento de Jean Bethke Elshtain (1981) em Public man, private woman: o sexo de uma mulher não deve ditar o que ela faz no mundo da educação ou do emprego, nem tampouco devem os princípios do estrito autointeresse tornar-se dominantes na esfera familiar. Mas Elshtain pelo menos apoia alguma fusão 
ou negociação de princípios através das fronteiras entre público e privado. Walzer, ao contrário, parece manter as numerosas distinções entre uma pluralidade de esferas separadas. Da perspectiva do gênero, o problema em relação a isso é que os muros que as pessoas erigem entre uma e outra área podem bloquear os tipos de paralelos que poderiam de outro modo traçar. Grande parte da liberação das mulheres dependeu de tomar os princípios considerados apropriados a um domínio e dizer que se aplicavam igualmente a outro. O progresso aconteceu precisamente rompendo os muros.

O feminismo tem que questionar a separação das esferas, e nesse sentido tem pouca confiança nas distinções que a democracia liberal tenta fazer. E, no entanto, aqui também alguma acomodação é possível. À parte floreios retóricos, poucas feministas abandonaram qualquer distinção e, na questão do direito de escolha da mulher, muitas incorporaram noções liberais do que é irredutivelmente uma questão privada, em seus argumentos a favor do aborto livre e legal. A reserva adicional que observei deriva antes da tradição republicana do que da liberal. Embora o feminismo seja frequentemente refém daqueles que dissolvem as diferenças de escala e espécie numa mistura amorfa, há distinções cruciais entre ser uma cidadã e ser uma pessoa simpática e cuidadosa. Uma sociedade plenamente democrática seria aquela em que as pessoas se respeitassem mutuamente e onde todas as relações, não importa quão pequeno ou íntimo o contexto, fossem permeadas pelo princípio de que todas as pessoas têm o mesmo peso. Ainda assim, haveria diferença de espécie entre o lar, o local de trabalho e o Estado.

Todas as relações podem tornar-se "políticas", mas uma parte do que isso significa é que todas podem tornar-se contextos em que temos que nos distanciar um pouco de nós mesmas. Temos que ser capazes de por em perspectiva nossos desejos e necessidades, de criar alguma distância momentânea de nossos entusiasmos e preconceitos de modo a reconhecer a significação do que os outros têm a dizer. Há uma diferença entre a abordagem que devemos adotar enquanto cidadãs e as questões mais particulares que com razão nos preocupam em nossa vida quotidiana. "A democratização da vida quotidiana” é um bom slogan que captura a importância da igualdade democrática em cada esfera da existência humana. Mas é enganadora se negar toda distinção entre a política e a vida quotidiana. A democracia não é uma questão de blocos de construção em que todos os tijolos são igualmente significativos e tudo o que importa é quantos podemos acrescentar. Então, 
enquanto o processo de decisão deve ser aberto e equilibrado no lar, nas escolas, no local de trabalho, não devemos olhar para essa democratização da sociedade civil como uma alternativa a uma vida pública revitalizada. As duas têm que andar de mãos dadas.

\section{A praga da reunião}

Isso nos leva a uma questão perene: com quanta participação popular a democracia pode lidar, e quanta cidadania ativa requer uma democracia “revitalizada?". Argumentei que o ordenamento sexual de nossas sociedades é tal que as mulheres precisam de uma política de transformação e mudança, e que, porque sua subordinação entra no modo como as mulheres percebem a si mesmas e a suas necessidades, isso coloca um alto valor na discussão e nas conversas. As democracias liberais operam na base de participação limitada e ocasional, e os eleitores são normalmente chamados a decidir entre dois ou mais partidos vagamente definidos, embrulhados em posições agradavelmente apresentadas. Não é coincidência que ela encontre seus apoiadores mais dedicados entre aqueles que resistem a mudanças radicais. $\mathrm{O}$ voto isolado amortece a imaginação política; em reuniões, ao contrário, podemos começar a conceber um leque mais amplo de opções e testar nosso poder potencial. As pessoas mudam de posição no curso de reuniões e discussões, e não só porque são levadas pelo entusiasmo de outros e concordam com coisas em que não acreditam. A mudança pode ser e muitas vezes é "real". Insatisfações vagas encontram expressão mais clara, ao mesmo tempo em que coisas que se acreditava inevitáveis podem começar a parecer abertas à reforma.

A política do gênero soma seu peso ao daqueles que veem o voto isolado como algo que oferece muito pouca amplitude para influenciar a agenda e introduzir novos tipos de problemas. Para qualquer grupo que esteja fora da política estabelecida, essa é uma queixa especialmente pertinente. As mulheres não podem (enquanto mulheres) ter grande peso num sistema que só lhes pede para registrar apoio ou rejeição para os partidos ou programas existentes. Pode ser que nenhuma das alternativas tenha qualquer proposta para as questões específicas das mulheres; e as mulheres podem não ser capazes de formular seus interesses sem um fórum em que possam falar.

Quando isso se liga aos problemas adicionais da relativa reclusão doméstica das mulheres, o feminismo aponta para uma democracia mais ativamente participativa do que tem sido oferecida na norma liberal. Mas, quanto mais 
participativa a democracia tenta ser, tanto mais discrimina entre mulheres e homens. Quanto mais ênfase põe na atividade e no envolvimento, mais ela tende a exagerar a influência dos que já têm maiores recursos de educação, charme ou tempo. É parte da natureza sexualmente dividida da sociedade contemporânea que as mulheres trabalhem mais tempo que os homens, mas com menor variedade de experiência ou tempo consumido na educação formal. A menos que haja mudança radical na organização do trabalho pago e não pago, elas continuarão a ser as menos capazes de sair para reuniões e de fazer-se ouvidas. A democracia liberal tem isso a seu favor: ao reduzir as demandas de participação a tão baixo nível, as torna mais genuinamente disponíveis para todos.

Em suas próprias experiências com a democracia participativa, o movimento das mulheres revelou tensões adicionais. As circunstâncias da democracia direta (face a face) nem sempre promovem a discussão aberta e, quando os ideais da igualdade democrática são muito elevados, o resultante tumulto de culpa e acusações e ressentimentos pode afastar as pessoas da política em geral. Há sérias dificuldades, mas no padrão geral dos "problemas da democracia” elas não ocupam tanto espaço. Muitos grupos devem passar por curvas semelhantes de experiências, nas quais o entusiasmo inicial pela igualdade democrática e pelo envolvimento leva, de uma fase de impaciência e amargura, a um compromisso mais sóbrio em fazer as coisas tão democráticas quanto possível nas condições do momento. Lembro-me do comentário de Eduard Bernstein sobre o socialismo, de que o movimento é tudo e o objetivo final é nada. No sentido de que uma democracia "plena" nunca poderá ser realizada, mas que fazemos tantas aproximações a ela quantas pudermos, o mesmo pode ser dito da democracia. Isso aceito, e a democracia concebida como um processo em lugar de um conjunto de ideais impossivelmente elevados, as tensões associadas com as decisões igualitárias (num movimento, partido, sindicato, comitê, no local de trabalho ou qualquer tipo de grupo) se tornam mais administráveis. Em tudo isso, é claro, estamos lidando com as pessoas que estão lá. Os verdadeiros problemas surgem quando as pessoas ainda não apareceram.

Quanto mais altas as demandas, menos amplo o envolvimento. Quanto mais participativa a política, menos capaz de responder aos que são passivos ou inertes. Parece haver uma escolha substantiva que os democratas enfrentam continuamente entre as igualdades precisas da democracia mínima e 
os riscos potenciais da participação mais intensa. Esta última é, de muitas maneiras, utópica e imanejável, mas a maior preocupação é que ela pode ser enviesada e produzir resultados não representativos. Quando os interesses entram em conflito, e ainda, o que é mais comum, quando uma minoria conseguiu uma concentração indevida de poder, só há um modo justo de resolver as disputas: dar peso igual a todos os indivíduos e dar a cada cidadão um voto. Não é que a democracia liberal tenha tido um desempenho brilhante em termos de capacidade de resposta, pois, como observado muitas vezes neste texto, ela opera num nível muito raso de consentimento que pode não ir além de decidir qual dos contendores deve governar. Sua maior virtude é que pelo menos ela distribui esse favor igualmente entre todos.

Repensar a democracia a partir da perspectiva do gênero não altera substancialmente os termos da escolha entre igualdade mínima e participação aumentada, e o feminismo não tem nenhuma visão nova que possa mudar esse dilema. O feminismo fortalece a defesa da democracia ativa, mas também sublinha a importância de dar a cada pessoa seu voto. Nessa questão central da democracia, as alternativas continuam as mesmas de antes. De um lado, a "democracia de uma sociedade cínica” (Mansbridge, 1980, p. 13), que pouco espera do envolvimento e olha a autoproteção como objetivo mais alto: uma democracia sem ambições, que não é inspiradora, que não nos dá satisfação moral. A despeito de sua perspicácia mundana, ela nunca desloca inteiramente as alternativas, cujos ideais reaparecem a cada momento. Esses contraideais, no entanto, trazem com eles suas próprias insatisfações.

Minha solução segue o tipo de "economia mista" que virou moda em nossos dias. Democracia significa que as pessoas tomam as decisões e continuará como uma formalidade exceto onde isso tiver lugar. As únicas maneiras substanciais em que se pode dizer que as pessoas decidem acontecem quando elas participam da decisão das agendas e influenciam as escolhas a que se chega. Escolher entre dois partidos que aparecem como se fosse do nada, e nem mesmo dizem o que pretendem fazer, não conta como decidir. As pessoas precisam de acesso contínuo a todos esses contextos, dentro e fora dos partidos políticos, no âmbito nacional e no local, nos quais poderão dar forma às decisões a serem tomadas. A maldição da reunião continua. Mas a democracia também significa que as pessoas são olhadas como iguais e não são mais importantes quando saem para mais reuniões. Ao argumentar pela maior descentralização das decisões, John Keane diz que precisamos de 
uma variedade de esferas "em que diferentes grupos de cidadãos poderiam participar se quisessem" (KEANE, 1988, p. 13), mas que as pessoas quererão se fazer ouvidas em diferentes graus e sobre tópicos diferentes. Algumas provavelmente nunca se farão ouvir. Se a participação não tivesse custos, poderíamos descartar essas pessoas como se indicassem, por sua ausência, que estão satisfeitas em que os outros decidam. Como a participação é de fato notavelmente custosa - em energia e muitas vezes em dignidade e tempo -, não podemos trilhar essa via.

Ainda que não discuta o problema nesses termos, John Keane sugere uma solução possível quando lista uma série de iniciativas para as quais o governo central poderia garantir recursos, mas deixa para os cidadãos locais a exata determinação de como esses recursos deveriam ser empregados. Assim, o governo poderia reservar certa quantidade de dinheiro para o cuidado das crianças, mas aqueles que decidirem envolver-se em organizações locais serão os que decidirão a forma desses cuidados. Esse é um bom exemplo, mas seu apelo está na noção semisubmersa do que é básico e do que é subsidiário. Quanto mais descentralizado se torna um serviço, mais ele variará de um lugar para outro - porque as pessoas diferem em suas preferências e ideias, mas também porque diferem no grau em que se envolvem e se tornam ativas. Em cada caso, as pessoas teriam que fazer escolhas entre qualidade e quantidade (deveriam melhorar os serviços ou aumentar o número das crianças atendidas?), e sobre os tipos e extensão dos cuidados (creches ou cuidadoras? A ênfase seria no aprendizado ou nas brincadeiras? Quão estruturado deveria ser o ambiente?). Às crianças que vivem em diferentes áreas seriam oferecidos diferentes tipos de serviços, e algumas áreas se sairiam melhor que outras.

Se aceitamos essa divergência como parte do que é uma democracia, isso decorre em parte de que o peso que damos à participação e à escolha é suficiente para equilibrar as desigualdades potenciais. É também, acredito, porque a forma precisa, a qualidade e a organização do trabalho com as crianças ainda não são consideradas como influências determinantes nas vidas das pessoas. Aceitamos mais prontamente a variação e a experimentação a esse respeito porque, certas ou erradas, as pessoas em sua maioria olham para os cuidados com os pré-escolares como uma questão subsidiária e não central. (Tanto pais como políticos demonstraram maior relutância em delegar plena responsabilidade a ativistas locais quando o que está em jogo é 
a organização das escolas). Quando se trata de questões em que há um maior grau de comprometimento, então o fato de que uma decisão será tomada numa reunião aberta em que todos em princípio podem participar não é considerado como proteção suficiente. As pessoas têm baixas expectativas sobre a medida em que podem envolver-se. Assim, enquanto podem estar preparadas para apoiar a democracia direta no âmbito de questões subsidiárias, preferirão o controle exercido através do voto quando as decisões forem relativas a questões "básicas". Sempre há riscos associados a decisões descentralizadas baseadas em reuniões, e o risco principal é que os ativistas não sejam representativos.

Se a igualdade democrática significa alguma coisa, é que a sociedade deve submeter suas decisões "últimas" a um fórum em que todos possam tomar parte. Realisticamente, isso significa o voto, em eleições nacionais e locais e, em algumas questões, referendos. Pode haver um cenário futuro, quando as pressões de tempo tiverem sido equilibradas entre mulheres e homens e as sociedades puderem elevar seus padrões de participação. Mas como o gênero não é o único determinante dos níveis de participação, isso requereria também muitas outras mudanças. Num futuro previsível, a democracia terá que se apoiar no minimalismo liberal para aquelas decisões vistas como as mais fundamentais, e as decisões só poderão ser estendidas à participação através de reuniões para as questões consideradas menos fundamentais. Que devemos pressionar por essa extensão em tantos contextos quantos possíveis deve, espero, ter ficado claro pelos argumentos desenvolvidos neste texto. Menos claro é que princípio determinaria quais decisões são básicas e quais não o são, mas isso ocorre porque é uma questão que só a política pode responder.

\section{Vozes de mulheres, questões de mulheres}

O último ponto a que quero voltar gira em torno da tensão entre as preocupações feministas e republicanas. As mulheres frequentemente falam no espetáculo de uma legislatura predominantemente masculina que decide se o aborto deve ser descriminalizado e observam com amargura que são elas que engravidam e que têm que cuidar da criança. De todas as questões políticas nas quais o gênero é pertinente, essa é a mais impressionante - e a relativa exclusão das mulheres das arenas onde essas decisões são tomadas é um exemplo ultrajante de quão pouco democráticas são as nossas democracias. Não é que os homens se oponham e as mulheres favoreçam o aborto: evidên- 
cias da Grã Bretanha, por exemplo, indicam que as mulheres sofrem mais que os homens na discussão da questão dos abortos tardios, se preocupam mais em pesar a proteção da mãe e a do feto, são menos superficiais sobre o que o aborto envolve. As experiências da gravidez e da maternidade geram um conjunto complexo e nuançado de atitudes, confirmando - se isso fosse preciso - que essa experiência deveria ter mais peso.

O corolário, porém, não é que os homens não devem ter opinião sobre a questão. Um dos efeitos colaterais mais ambivalentes dos últimos vinte e cinco anos de atividade feminista é o autorebaixamento praticado por muitos homens "simpáticos" à causa. Assim como os liberais brancos às vezes decidem silenciar em questões de raça e etnicidade, também homens progressistas às vezes abdicam de suas responsabilidades no que agora concebem como uma questão "das mulheres". Ao aceitar a incongruência na legislação masculina em matérias como o aborto, cuidados com as crianças ou ação afirmativa, eles podem estar se desculpando por sua presunção prévia, e perguntando às mulheres o que devem fazer. Um problema com isso é que parece uma aceitação muito fácil de que há uma posição das mulheres; outra deficiência, mais urgente, é que o palco pode ser deixado àqueles menos reticentes em relação a seu direito de decidir.

A dificuldade seguinte é a implicação de que apenas aqueles com a experiência têm algo legítimo a dizer. Darei um exemplo recente da política dos EUA. Quando desafiado a justificar seu apoio político ao aborto, apesar de suas próprias objeções morais pessoais, o governador Mario Cuomo observou que "há um elemento absurdo ou incongruente em homens que fazem leis sobre algo que nunca poderão experimentar - a gravidez" (apud Wills, 1990). Como argumenta Gary Wills, isso entra em conflito com

os valores cidadãos do republicanismo, onde todos na comunidade são convidados a pensar em conjunto sobre todas as questões morais. Não dizemos, numa república, que só os militares podem decidir sobre o papel dos militares na vida pública, que só a academia pode formular questões educacionais, que só os crentes podem formular questões religiosas, e assim por diante. Cuomo parece estar assumindo uma posição lúcida quando se desculpa, como homem, por falar sobre o aborto; mas é uma posição não republicana (Wills, 1990).

Dadas as críticas feministas aos “valores cidadãos”, essa observação carece de maior peso, mas argumentei neste texto que esses valores deveriam nos 
fazer parar para pensar. Todos os membros de uma comunidade política são formados e limitados por suas experiências, o que é parte do argumento de que todas essas experiências devem ganhar sua voz. Mas qualquer política que olha para a mudança e para a transformação não pode deixar as coisas por aí.

O liberal clássico lida com tais problemas ao estabelecer uma região da existência privada em que cada uma de nós faz suas escolhas morais ou religiosas, e ninguém mais tem o direito de reclamar. $\mathrm{O}$ pluralista do século vinte os enfrenta com o argumento (em geral desonesto) de que todos os grupos são livres para contestar-se mutuamente, assim contribuindo para o resultado final. De uma perspectiva que procura reformar ou revolucionar as condições de nossa existência, nenhuma dessas opções é adequada, pois ambas aceitam os limites da experiência como algo que não podemos superar.

A alternativa mais extrema à democracia liberal é a que se associa à tradição marxista, algumas versões da qual antecipam um futuro além de todo conflito significativo, em que as pessoas agirão homogeneamente como uma só. Os argumentos contrários são esmagadores demais para serem reencenados, mas uma coisa é negar voz ao conflito e outra aceitar todos os conflitos como finais. A recente ênfase feminista sobre a diferença e a heterogeneidade deve ser considerada uma correção necessária às teorias e práticas políticas que excluíram o sexo (entre outras coisas) da arena política. Isso deve ser visto, contudo, como um ponto a partir do qual as desigualdades podem ser enfrentadas e reduzidas. O requisito fundamental é a presença política das mulheres: o que não quer dizer que só as mulheres podem falar das questões "das mulheres", que elas devem falar apenas como sexo.

Ao fim do século vinte, dois desenvolvimentos principais definem a cena. O primeiro e mais dramático é a extensão das práticas liberais democráticas do sufrágio universal, de eleições livres e da competição partidária - não apenas na antiga União Soviética e na Europa Oriental, mas também nos países do antigo mundo colonizado. "Uma pessoa, um voto" agora parece iminente mesmo nos países mais antidemocráticos, como a África do Sul, enquanto a mão pesada dos regimes militares e os estados de partido único em outras partes da África são novamente desafiados. Entre aqueles que acham a democracia liberal fraca e inadequada, há considerável ansiedade de que esses ganhos possam varrer as críticas e que, gozando liberdades que lhes eram negadas, as pessoas esqueçam por uma geração a substância de 
suas avaliações anteriores. Os problemas que as feministas levantaram, que se fundam sobre a análise crítica do liberalismo e a estendem, devem ajudar a enfrentar esse risco.

O outro desenvolvimento principal é que os mitos da homogeneidade estão sendo estilhaçados, da maneira mais positiva pela consciência do gênero e pela diferenciação étnica, e de modo mais ambivalente pelo fundamentalismo religioso e pelo "novo" nacionalismo da antiga União Soviética e da Europa Oriental. As preocupações do feminismo contemporâneo são muito apropriadas a esse desenvolvimento, e colocam diante de nós algumas das questões-chave que os democratas terão que enfrentar. As teóricas políticas feministas levantaram críticas importantes ao indivíduo abstrato e às falsas universalidades de boa parte do pensamento iluminista, e hoje as feministas lideram a procura por uma nova política baseada na diversidade e na diferença. Eu preferiria não percorrer alguns dos caminhos que se abrem. Mas todo o debate é crucial para o futuro do pensamento democrático. Temos que encontrar uma linguagem política que possa reconhecer a heterogeneidade e a diferença, mas que não capitule para um essencialismo que nos defina por apenas um aspecto. Os argumentos que hoje percorrem os círculos feministas são um guia satisfatório nesse terreno.

\section{Referências bibliográficas}

ARBLASTER, Anthony. 1987. Democracy. Buckingham: Open University Press.

EISENSTEIN, Zikkah. 1989. The female body and the law. New Jersey: University of California Press.

ELSHTAIN, Jean Bethke. 1981. Public man, private woman: women in social and political thought. Princeton: Princeton University Press.

FUKUYAMA, Francis. 1989. "The end of history?". The National Interest, n. 16, p. 3-18.

KEANE, John, 1988. Democracy and civil society. London: Verso.

LUKES, Steven, 1985. Marxism and morality. New York: Oxford University Press.

MANSBRIDGE, Jane J. 1980. Beyond adversary democracy. New York: Basic Books.

MARX, Karl \& ENGELS, Friedrich. 1975. Collected works, vol. III. London: Lawrence \& Wishart. 
PARMAAR, Pratibha. 1989. "Other kinds of dreams". Feminist Review, n. 31, p. 55-65.

PATEMAN, Carole. 1988. The sexual contract. Cambridge/California: Polity Press/ Stanford University Press.

PHILLIPS, Anne. 1987. Divided loyalties: dilemmas of sex and class. London: Virago.

POPPER, Karl. 1945. The open society and its enemies. London: Routledge and Kegan Paul.

WALZER, Michael. 1983. Spheres of justice: a defense of pluralism and equality. New York: Basic Books.

. 1984. "Liberalism and the art of separation". Political Theory, v. 12, n. 3, p. 315-330.

WILLS, Gary. 1990. "Mario Cuomo's trouble with abortion." New York Review of Books, n. 28 (online).

YOUNG, Iris Marion. 1989. "Polity and group difference: a critique of the idea of universal citizenship". Ethics, n. 99, p. 250-274.

\section{Resumo}

O texto discute os limites das democracias liberais a partir das desigualdades de gênero. As discrepâncias entre o corpo dos eleitos e o conjunto dos eleitores são o ponto de partida para a proposta de reconceitualizar a democracia tendo em mente as diferenças de gênero. A representação de grupos, e não de indivíduos, é o primeiro aspecto analisado, considerando padrões sistemáticos de exclusão e problemas relativos às identidades dos grupos. Esse ponto é retomado na parte final do texto, em que a autora estabelece distinções entre heterogeneidade de experiências e essencialização das identidades e interesses. O texto analisa, ainda, a acomodação entre igualdade na esfera pública e subordinação na esfera privada, com a convivência entre direitos formalmente iguais e privilégios de grupos sociais específicos, assim como os filtros que se impõem a uma participação política mais equânime.

Palavras-chave: democracia; liberalismo; gênero; desigualdades; diferenças.

\section{Abstract}

This article analyses the limitations of liberal democracies from the point of view of gender inequalities. The discrepancy of composition between the elected body and the whole electorate serve as the point of departure for a proposal to re-conceptualize democracy taking into account gender differences. Group representation instead of that of individuals is the first aspect analyzed considering systematic patterns of exclusion 
and problems related to group identities. The point is taken again in the final section of the text, where the author establishes distinctions between experience heterogeneity and the essentialization of identities and interests. The text also analyzes the balance of equality in the public sphere and subordination in the private sphere, considering the contradiction between formally equal rights and privileges to specific social groups, as well as the filters before a fairer political participation.

Key words: democracy; liberalism; gender; inequalities; differences. 